\title{
Ability of Hydroxyapatite Synthesized from Waste Oyster Shells to Remove Fluoride Ions
}

\author{
Sota Terasaka*1, Masanobu Kamitakahara*2, Taishi Yokoi and Hideaki Matsubara \\ Graduate School of Environmental Studies, Tohoku University, Sendai 980-8579, Japan
}

Calcium carbonates, the main component of seashell waste, can be converted to hydroxyapatite (HA) via phosphate solution treatment. HA can remove $\mathrm{F}^{-}$from water, as recommended by the World Health Organization (WHO), and HA particles of small sizes and/or large amounts are expected to remove $\mathrm{F}^{-}$more effectively. To control the size and amount of synthesized $\mathrm{HA}$, oyster shells were treated in the $\left(\mathrm{NH}_{4}\right)_{2} \mathrm{HPO}_{4}$ solution whose $\mathrm{pH}$ value was adjusted to 10 at $4-120^{\circ} \mathrm{C}$ for $24 \mathrm{~h}$. The HA particle size and amount increased with increasing reaction temperature. The samples' abilities to remove $\mathrm{F}^{-}$were evaluated by immersing them in $\mathrm{F}^{-}$-containing solutions. The sample treated at $30^{\circ} \mathrm{C}$ removed $\mathrm{F}^{-}$the most effectively, achieving a $\mathrm{F}^{-}$concentration below $1.5 \mathrm{mg} \cdot \mathrm{dm}^{-3}$, which is the level recommended by the WHO. The $\mathrm{HA}$ surface area is important in $\mathrm{F}^{-}$removal. [doi:10.2320/matertrans.M2015149]

(Received April 15, 2015; Accepted June 8, 2015; Published July 17, 2015)

Keywords: environmental purification material, hydroxyapatite, oyster shell, fluoride ion

\section{Introduction}

Great quantities of waste seashells are generated as a result of shellfish consumption in Japan. ${ }^{1)}$ Although seashells are mainly composed of calcium carbonate $\left(\mathrm{CaCO}_{3}\right){ }^{2)}$ they are not effectively used, and their management is problematic. If waste seashells can be utilized, the amount of waste seashells will be reduced. Calcium carbonates can be changed into hydroxyapatite $\left[\mathrm{Ca}_{10}\left(\mathrm{PO}_{4}\right)_{6}(\mathrm{OH})_{2}: \mathrm{HA}\right]$ by treatment with phosphate-containing solutions, ${ }^{3-5)}$ and attempts to synthesize HA from coral, $\left.{ }^{6}\right)$ egg-shells, ${ }^{7)}$ and seashells, ${ }^{1,8,9)}$ which are also mainly composed of calcium carbonate, have been reported. When waste seashells are changed into HA, the products are expected to be useful as environmental purification materials because HA can remove harmful ions such as $\left.\mathrm{Pb}^{2+},{ }^{10-12)} \mathrm{Cd}^{2+}, 1,11-13\right) \mathrm{Co}^{2+},{ }^{14)}$ and $\mathrm{F}^{-15-21)}$ from water. Among these harmful ions, $\mathrm{F}^{-}$was the focus of the present study. The ingestion of water with a $\mathrm{F}^{-}$concentration above $1.5 \mathrm{mg} \cdot \mathrm{dm}^{-3}$ causes dental and skeletal disorders. ${ }^{17-20)}$ The World Health Organization (WHO) has recommended a $\mathrm{F}^{-}$concentration level of less than $1.5 \mathrm{mg} \cdot \mathrm{dm}^{-3}$ in drinking water. ${ }^{22)}$ However, the ground water in many areas has a very high $\mathrm{F}^{-}$concentration. ${ }^{22)} \mathrm{HA}$ has been reported to remove $\mathrm{F}^{-}$by the exchange reaction of $\mathrm{OH}^{-}$and $\mathrm{F}^{-}$on the HA surface, ${ }^{15)}$ so the composition and shape of HA are important factors in $\mathrm{F}^{-}$removal. The composition and the shape of HA, which is synthesized from calcium carbonate with phosphatecontaining solution, is changed significantly by the reaction conditions. $^{3,9)}$ This feature implies that the properties of $\mathrm{HA}$ as an environmental purification material can be also controlled. However, the conditions of HA synthesis from oyster shells that would optimize $\mathrm{F}^{-}$removal had not been determined previously. We speculated that the particle size and amount of HA obtained from oyster shells would depend significantly on the reaction temperature. Specifically, we hypothesized that lower-temperature treatment would prevent HA crystal growth, while higher-temperature treatment would promote HA formation. It is expected that the reaction

\footnotetext{
${ }^{* 1}$ Graduate Student, Tohoku University

${ }^{* 2}$ Corresponding author, E-mail: kamitaka@mail.kankyo.tohoku.ac.jp
}

temperature optimal for $\mathrm{F}^{-}$removal material exists in the balance of the particle size and amount of HA. Thus, it was decided to focus on the relationship between the removal of $\mathrm{F}^{-}$by $\mathrm{HA}$ and the particle size and amount of HA synthesized from the oyster shells.

In the present study, HA was synthesized from oyster shells by treatment with a phosphate-containing solution at different temperatures, and its ability to remove $\mathrm{F}^{-}$was examined.

\section{Materials and Methods}

\subsection{Preparation of samples}

The oyster shell was obtained in Japan. The shell was ground, washed with distilled water, and dried at $90^{\circ} \mathrm{C}$ overnight. The oyster shell powder was sieved to obtain particles $100-300 \mu \mathrm{m}$ in size. It was assumed that the oyster shell was composed of only calcium carbonate. Then, $0.33 \mathrm{~g}$ of the oyster shell powder was placed into a Teflon ${ }^{\circledR}$-lined sealed vessel together with $20 \mathrm{~cm}^{3}$ of a $0.1 \mathrm{~mol} \cdot \mathrm{dm}^{-3}$ $\left(\mathrm{NH}_{4}\right)_{2} \mathrm{HPO}_{4}$ solution with $\mathrm{pH} 10$ to achieve a $\mathrm{Ca} / \mathrm{P}$ molar ratio of 1.7. The $\left(\mathrm{NH}_{4}\right)_{2} \mathrm{HPO}_{4}$ solution was prepared by dissolving $\left(\mathrm{NH}_{4}\right)_{2} \mathrm{HPO}_{4}$ (Wako Pure Chemical Industries, Ltd., Osaka, Japan) in distilled water, and its $\mathrm{pH}$ value was maintained at 10 by the addition of an $\mathrm{NH}_{3}$ solution (Wako Pure Chemical Industries, Ltd., Osaka, Japan). The sealed vessels were stored at $4-120^{\circ} \mathrm{C}$ for $24 \mathrm{~h}$. It was expected that lower temperatures would prevent HA crystal growth and that higher temperatures would promote HA formation. The samples treated at $4^{\circ} \mathrm{C}, 30^{\circ} \mathrm{C}, 60^{\circ} \mathrm{C}$, and $120^{\circ} \mathrm{C}$ were defined as OS4, OS30, OS60, and OS120, respectively. The sample without treatment, namely the original oyster shell, was defined as OS.

The crystalline phases of the samples were examined by X-ray diffractometry (XRD, RINT2200VL; Rigaku, Tokyo, Japan) using $\mathrm{CuK} \alpha$ radiation operating at $40 \mathrm{kV}$ and $40 \mathrm{~mA}$. The contents of the crystalline phases of the samples were calculated from diffraction peaks of the samples. ${ }^{23)} I_{\text {calcite }}$ at $2 \theta=29.4^{\circ}((104)$ plane $)$ and $I_{\mathrm{HA}}$ at $2 \theta=25.9^{\circ}((002)$ plane $)$ were measured, and the ratio $I_{\mathrm{HA}} /\left(I_{\text {calcite }}+I_{\mathrm{HA}}\right)$ was calculated, where $I$ is the peak area of the diffraction peak 
derived from the indicated crystalline phase. The crystalline phase contents of the samples were calculated from the calibration line. The calibration line was determined from samples in which the OS sample and commercial HA (Ube Material Industries, Ltd., Yamaguchi, Japan) were mixed in ratios of 1 to 0,3 to 1,1 to 1,1 to 3 , and 0 to 1 . The morphologies of the samples were observed using scanning electron microscopy (SEM, SU8000; Hitachi, Tokyo, Japan) without any coating. The elemental analyses of the sample surfaces were conducted by using energy dispersive X-ray spectroscopy (EDS, NORAN System 7; Thermo Fisher Scientific K.K., Kanagawa, Japan). The specific surface areas of the samples were examined by the $\mathrm{N}_{2}$-BET method using an Autosorb-iQ ASIQM0000-3 (Quantachrome Instruments, Florida, USA).

\subsection{Removal of $\mathbf{F}^{-}$}

The abilities of the samples to remove $\mathrm{F}^{-}$were evaluated. A $20 \mathrm{mg} \cdot \mathrm{dm}^{-3} \mathrm{~F}^{-}$solution was prepared by dissolving $\mathrm{NaF}$ (Wako Pure Chemical Industries, Ltd., Osaka, Japan) in distilled water. Then, $0.15 \mathrm{~g}$ of the particular sample being examined was added to $10 \mathrm{~cm}^{3}$ of the $\mathrm{F}^{-}$solution. The solution was maintained at $30^{\circ} \mathrm{C}$ for $6 \mathrm{~h}$ while shaking at $125 \mathrm{rpm}$. After $6 \mathrm{~h}$, a supernatant solution was obtained by centrifuge separation. The $\mathrm{pH}$ value of the solution was measured by a $\mathrm{pH}$ electrode (9631-10D, Horiba, Ltd., Kyoto, Japan). Then, $3 \mathrm{~cm}^{3}$ of total ionic strength adjustment buffer $(\text { TISAB })^{24)}$ and $6.5 \mathrm{~cm}^{3}$ of distilled water were added to $6.5 \mathrm{~cm}^{3}$ of supernatant liquid, and the $\mathrm{F}^{-}$concentration in the solution was measured by a $\mathrm{F}^{-}$electrode (6561-10C, Horiba, Ltd., Kyoto, Japan). The $\mathrm{F}^{-}$concentration of the original solution was calculated by doubling the concentration measured by the $\mathrm{F}^{-}$electrode. The removal tests were conducted three times for each sample.

\section{Results and Discussion}

\subsection{Characterization of the samples}

Figure 1 shows the XRD patterns of the samples. The crystalline phase of the original oyster shell was calcite (PDF\#47-1743). Diffraction peaks from HA (PDF\#89-6439) were detected in the samples treated at $30^{\circ} \mathrm{C}$ or more. The intensities of the HA diffraction peaks increased with increasing temperature. On the other hand, calcite remained in the samples after the treatment. The intensities of the diffraction peaks from calcite decreased with increasing temperature. These results indicate that HA was generated by the reaction of calcite in the oyster shell with $\mathrm{PO}_{4}{ }^{3-}$ in the treatment solution at $30^{\circ} \mathrm{C}$ or more and that OS30, OS60, and OS120 were $\mathrm{HA} /$ calcite composite materials. The samples were assumed to be composed of only calcite and hydroxyapatite, and the contents of the crystalline phases in the samples were calculated from the intensities of the XRD peaks. Table 1 shows the contents of the crystalline phases. The HA content increased with increasing reaction temperature. This result indicates that HA generation proceeded more efficiently with an increased reaction temperature.

SEM photographs of the sample surfaces are shown in Fig. 2. The particles in OS and OS4 appear nearly identical, both displaying plate-like shapes. In contrast, the particles in

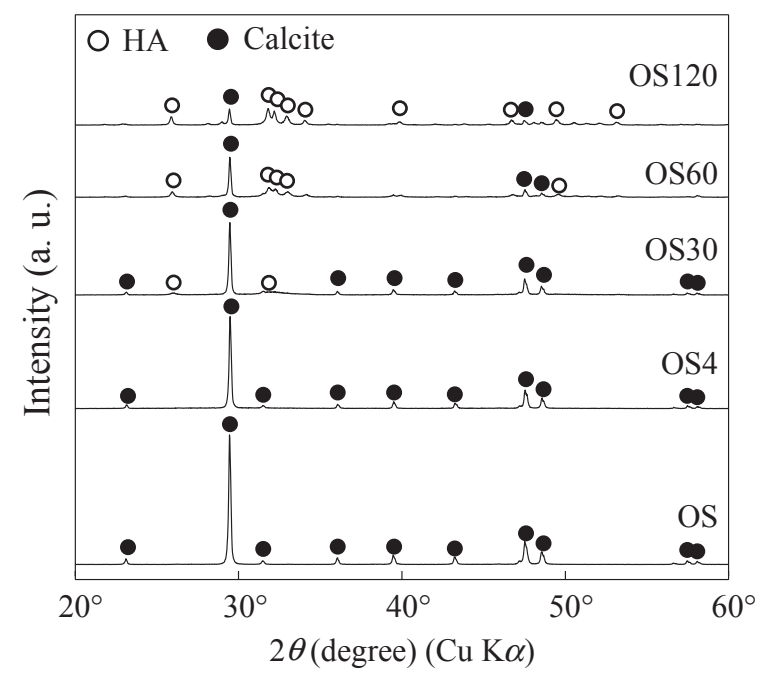

Fig. 1 XRD patterns of samples.

Table 1 Crystalline phase contents and specific surface areas of the samples.

\begin{tabular}{|c|c|c|c|}
\hline \multirow{2}{*}{ Sample } & \multicolumn{2}{|c|}{ Content of crystalline phase (mass $\%$ ) } & \multirow{2}{*}{$\begin{array}{l}\text { Specific surface area, } S \\
\qquad / \mathrm{m}^{2} \cdot \mathrm{g}^{-1}\end{array}$} \\
\hline & HA & Calcite & \\
\hline OS & 0 & 100 & 3.7 \\
\hline OS4 & 0 & 100 & 10.0 \\
\hline OS30 & 31 & 69 & 54.4 \\
\hline OS60 & 57 & 43 & 30.2 \\
\hline OS120 & 81 & 19 & 15.4 \\
\hline
\end{tabular}

OS30 exhibit whisker-like shapes, and the particles in OS60 and OS120 show rod-like shapes. Thus, the particles in the samples treated at $30^{\circ} \mathrm{C}, 60^{\circ} \mathrm{C}$, and $120^{\circ} \mathrm{C}$ were significantly different than those of OS and OS4. Comparing the SEM photographs in Fig. 2, no significant difference is observed between the surfaces of OS4 and OS. However, the surfaces of the samples treated at $30^{\circ} \mathrm{C}$ or more differ significantly from that of OS. It is speculated that the particles found in the samples treated at $30^{\circ} \mathrm{C}$ or more were HA because these particles cannot be observed in the OS image, in which the particles are uniformly distributed across the sample surface.

The long and short axes of these particles were measured from the SEM photographs. The lengths of the long and short axes of OS30 were determined to be about $180 \mathrm{~nm}$ and $20 \mathrm{~nm}$, respectively, while those of OS60 were about $220 \mathrm{~nm}$ and $50 \mathrm{~nm}$, respectively, and those of OS120 were about $280 \mathrm{~nm}$ and $110 \mathrm{~nm}$, respectively. From these results, it can be seen that the HA particle size increased with increasing reaction temperature.

The specific surface areas of the samples as determined by the $\mathrm{N}_{2}$-BET method are also shown in Table 1. The specific surface area of OS30 is largest among the studied samples. The areas of the samples treated at $30^{\circ} \mathrm{C}$ or less increase with increasing reaction temperature, while those of the samples treated at $30^{\circ} \mathrm{C}$ or more decrease with increasing reaction temperature. Comparing the HA particle sizes and specific surface areas of the samples, it is speculated that small HA crystals were generated by treatment at $30^{\circ} \mathrm{C}$, yielding a large 

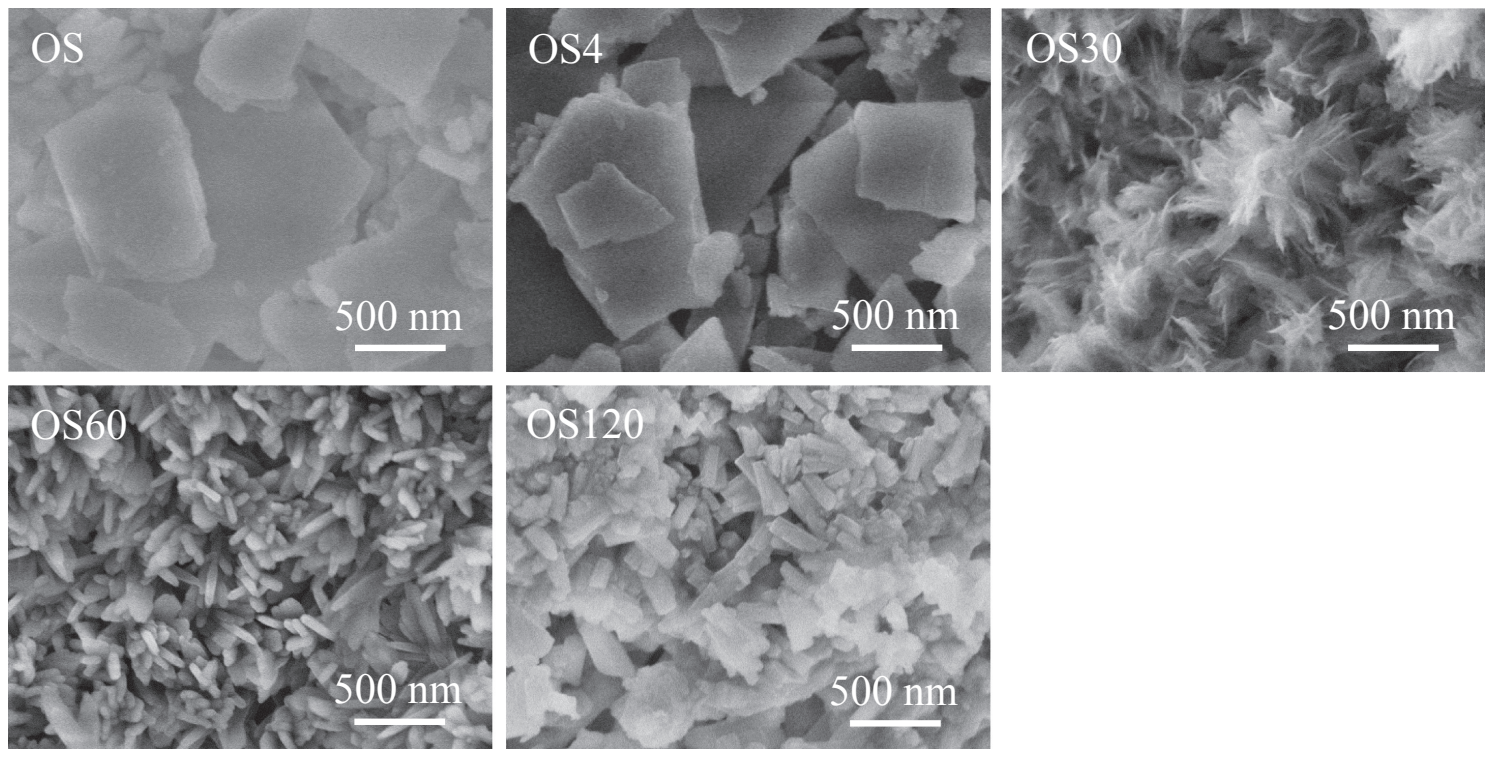

Fig. 2 SEM photographs of sample surfaces.

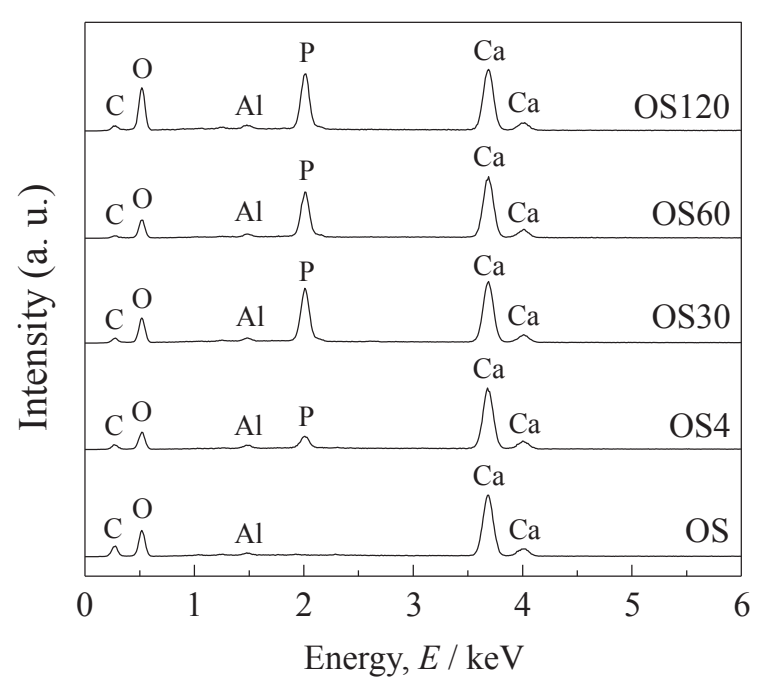

Fig. 3 EDS spectra of samples. Peak intensities were normalized by peak intensity of $\mathrm{Ca}$.

specific surface area for OS30. HA crystals were not generated by treatment at $4^{\circ} \mathrm{C}$, so the specific surface areas of OS and OS4 are smaller than that of OS30. On the other hand, HA crystal growth was promoted at treatment temperatures of $30^{\circ} \mathrm{C}$ or more, so the specific surface areas of OS60 and OS120 decreased with increasing reaction temperature.

Figure 3 shows the EDS spectra of the samples. Substantial $\mathrm{Ca}, \mathrm{C}$, and $\mathrm{O}$ peaks and small $\mathrm{Al}$ peak were detected in all of the samples. Additionally, a small $\mathrm{P}$ peak was detected on OS4, and large P peaks were detected on OS30, OS60 and OS120. The small Al peaks are due to the holder on which the samples were fixed. Although the surface morphology of OS4 is almost same as that of OS, P was first detected on OS4 after treatment. Based on this observation, it is likely that a small amount of amorphous calcium phosphate formed in OS4. The P peaks that were detected on OS30, OS60, and OS120 are larger than that detected on OS4 because HA had formed.

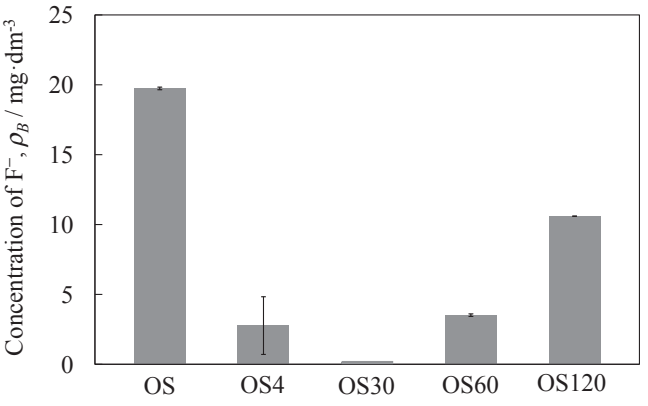

Fig. $4 \mathrm{~F}^{-}$concentration after removal test.

\subsection{Removal of $\mathrm{F}^{-}$}

Figure 4 shows the $\mathrm{F}^{-}$concentration of each solution after the removal test. Except for OS, all of the samples yielded decreased $\mathrm{F}^{-}$concentrations in their solutions. These results indicate that an untreated oyster shell cannot remove $\mathrm{F}^{-}$, while treated oyster shells gain the ability to remove $\mathrm{F}^{-}$.

In OS30, OS60, and OS120, HA crystals were generated by treatment at $30^{\circ} \mathrm{C}$ or more, so $\mathrm{F}^{-}$was removed by $\mathrm{HA}$ in these samples. On the other hand, OS4 also removed $\mathrm{F}^{-}$ although HA crystals were not generated. As shown in Fig. 3, P was detected in OS4. Thus, amorphous calcium phosphate likely formed on the OS4 surface, removing $\mathrm{F}^{-}$. As amorphous calcium phosphate exists in a metastable phase, it may transform into HA by incorporating $\mathrm{F}^{-}$. OS30 was able to remove $\mathrm{F}^{-}$the most effectively and achieved a $\mathrm{F}^{-}$ concentration less than $1.5 \mathrm{mg} \cdot \mathrm{dm}^{-3}$, which is recommended by the WHO. ${ }^{22)}$ The $\mathrm{pH}$ value of the solution before the removal test was $6.28 \pm 0.11$. The $\mathrm{pH}$ values of the solutions after the removal test for OS, OS4, OS30, OS60 and OS120 were $8.33 \pm 0.10,7.81 \pm 0.03,8.22 \pm 0.02,8.15 \pm 0.03$ and $7.86 \pm 0.03$, respectively. The $\mathrm{pH}$ values of the solutions increased after the removal test for all of the samples. The increases in the $\mathrm{pH}$ values of the solutions after the removal test for OS and OS4 are due to the dissolution of the calcite which is the main component of OS and OS4. The increases in the $\mathrm{pH}$ values of the solutions after the removal test for 


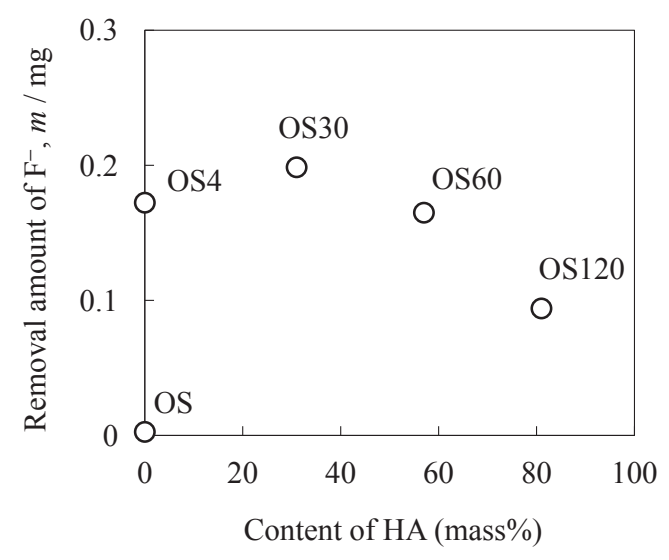

Fig. 5 Relationship between removed amount of $\mathrm{F}^{-}$and HA content in samples.

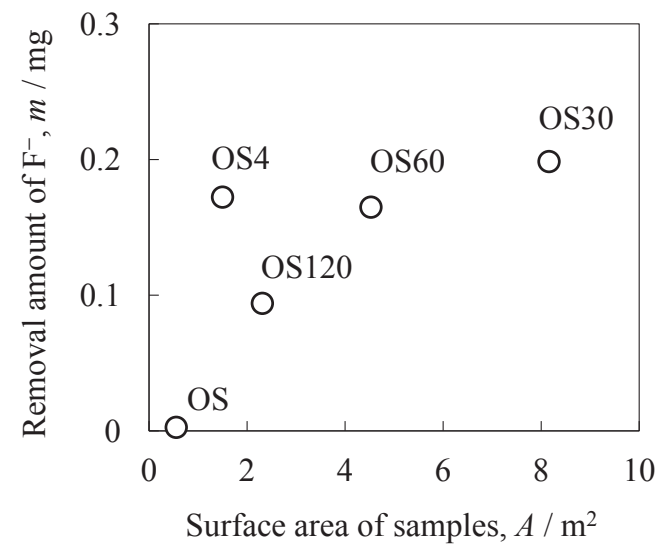

Fig. 6 Relationship between removed amount of $\mathrm{F}^{-}$and sample surface area.

OS30, OS60 and OS120 are due to the dissolution of the calcite remaining in the samples and the release of $\mathrm{OH}^{-}$from $\mathrm{HA}$ in the samples when HA incorporates $\mathrm{F}^{-}$.

The relationship between the amount of $\mathrm{F}^{-}$removed and HA content is plotted in Fig. 5. No linear relationship between the HA content and amount of $\mathrm{F}^{-}$removed is observed. On the other hand, the plot showing the relationship between the amount of $\mathrm{F}^{-}$removed and sample surface area (Fig. 6) reveals that larger sample surface areas correspond to the removal of more $\mathrm{F}^{-}$. It can be assumed that the increased sample surface areas are due to HA because the specific surface areas before HA formation were quite small and increased with HA formation but decreased with increased HA particle size. It is speculated from Figs. 5 and 6 that the exchange reaction of $\mathrm{OH}^{-}$and $\mathrm{F}^{-}$stopped at the $\mathrm{HA}$ crystal surfaces and consequently did not proceed inside the HA crystals. Therefore, the specific surface area of HA is a very important factor in determining the ability of a material to remove $\mathrm{F}^{-}$. This study revealed that $\mathrm{F}^{-}$removal material could be synthesized at very low temperatures. It is speculated that HA synthesized from oyster shells has the ability to remove great quantities of $\mathrm{F}^{-}$with handleability for application because small HA particles formed on the oyster shell surfaces. Thus, HA synthesized from oyster shells is expected to be a promising $\mathrm{F}^{-}$removal material.

\section{Conclusion}

HA was prepared by the treatment of oyster shells with a phosphate-containing solution at different temperatures. The sample obtained at $30^{\circ} \mathrm{C}$ was able to reduce the $\mathrm{F}^{-}$ concentration to less than $1.5 \mathrm{mg} \cdot \mathrm{dm}^{-3}$. The surface area of HA was revealed to be a more important factor for $\mathrm{F}^{-}$ removal than is the amount of HA. Treatment at $30^{\circ} \mathrm{C}$ was determined to be the most suitable reaction condition because the smallest HA particles were obtained. Thus, HA synthesized from oyster shells is expected to be a promising $\mathrm{F}^{-}$removal material.

\section{REFERENCES}

1) M. S. Islam, D. Ueno, T. Someya and K. Inoue: Environ. Control. Biol. 50 (2012) 81-89.

2) S. W. Lee, Y. M. Kim, R. H. Kim and C. S. Choi: Micron 39 (2008) 380-386.

3) W. Park, M. Kamitakahara, T. Nagamori and K. Ioku: Phosphorus. Res. Bull. 25 (2011) 72-77.

4) M. Yoshimura, P. Sujaridworakun, F. Koh, T. Fujiwara, D. Pongkao and A. Ahniyaz: Mater. Sci. Eng. C 24 (2004) 521-525.

5) K. Ishikawa, S. Matsuya, X. Lin, Z. Lei, T. Yuasa and Y. Miyamoto: J. Ceram. Soc. Japan 118 (2010) 341-344.

6) D. M. Roy and S. K. Linnehan: Nature 247 (1974) 220-222.

7) F. Habib, S. Alam, N. Zahra, M. Irfan and W. Iqbal: J. Chem. Soc. Pak. 34 (2012) 584-588.

8) A. F. Lemos, J. H. G. Rocha, S. S. F. Quaresma, S. Kannan, F. N. Oktar, S. Agathopoulos and J. M. F. Ferreira: J. Eur. Ceram. Soc. 26 (2006) 3639-3646.

9) T. Matsui, N. Tanaka and T. Takahashi: J. Soc. Inorg. Mater. Japan 22 (2015) 3-11 [in Japanese].

10) Y. Xu and F. W. Schwartz: J. Contam. Hydrol. 15 (1994) 187-206.

11) I. Smičiklas, A. Onjia, S. Raičević, Đ. Janaćković and M. Mitrić: J. Hazard. Mater. 152 (2008) 876-884.

12) C. K. Lee, H. S. Kim and J. H. Kwon: Environ. Eng. Res. 10 (2005) 205-212.

13) A. Corami, S. Mignardi and V. Ferrini: J. Colloid Interface Sci. 317 (2008) 402-408.

14) I. Smičiklas, S. Dimović, I. Plećaš and M. Mitrić: Water Res. 40 (2006) 2267-2274.

15) V. Sternitzke, R. Kaegi, J. N. Audinot, E. Lewin, J. G. Hering and C. A. Johnson: Environ. Sci. Technol. 46 (2012) 802-809.

16) S. Gao, R. Sun, Z. Wei, H. Zhao, H. Li and F. Hu: J. Fluor. Chem. 130 (2009) 550-556.

17) C. S. Sundaram, N. Viswanathan and S. Meenakshi: J. Hazard. Mater. 155 (2008) 206-215.

18) V. E. Badillo-Almaraz, J. A. Flores, H. Arriola, F. A. López and L. Ruiz-Ramirez: J. Radioanal. Nucl. Chem. 271 (2007) 741-744.

19) L. E. L. Hammari, A. Laghzizil, P. Barboux, K. Lahlil and A. Saoiabi: J. Hazard. Mater. 114 (2004) 41-44.

20) M. Jiménez-Reyes and M. Solache-Ríos: J. Hazard. Mater. 180 (2010) 297-302.

21) S. Terasaka, M. Kamitakahara, T. Yokoi and K. Ioku: J. Ceram. Soc. Japan 122 (2014) 995-999.

22) J. Fawell, K. Bailey, J. Chilton, E. Dahi, L. Fewtrell and Y. Magara: Fluoride in Drinking-water, (IWA, London, 2006).

23) L. Alexander and H. P. Klug: Anal. Chem. 20 (1948) 886-889.

24) M. S. Frant and J. W. Ross, Jr.: Anal. Chem. 40 (1968) 1169-1171. 